\title{
Case Report of Jelly Fish Stinging in Bay of Bengal - A Report from Bangladesh
}

\author{
Mohammad Main Uddin ${ }^{1}$, Abul Barkat Muhammad Adnan ${ }^{2}$, Md. Shaheen Abdur Rahman Chowdhury ${ }^{1}$, Mamun-Al- \\ Mahtab $^{2}$. \\ ${ }^{1}$ Department of Medicine, Cox's Bazar Medical College, Cox's Bazar, ${ }^{2}$ Department of Hepatology, Cox's Bazar Medical College, Cox's Bazar, \\ ${ }^{3}$ Department of Hepatology, Bangabandhu Sheikh Mujib Medical University, Dhaka
}

\begin{abstract}
:
Introduction: Jelly fish or jellies are the members of the phylum Cnidaria (Coelenterata), consisting of a gelatinous umbrella-shaped bell and trailing tentacles. Sting contains toxic peptide, phospholipase A and histamine-liberating factor. Jelly fish stinging in Bangladesh is rare. Yet, from a management point of view, this epizoonozis might gain importance given the ever-growing popularity of seaside fishering and tourism. We are presenting a case of jelly fish contact illness in Cox's Bazar Medical College. Case Report: A 30 year old male patient was stung by a jellyfish while fishering in the Bay of Bengal near Teknaf of Cox's Bazar District on 3rd June' 2013. A couple of minutes later urticaria were formed in the contact area accompanied by a burning and sore sensation. Within few minutes he developed severe abdominal pain, bodyache and paresthaesia. Immediate decontamination was done by patient himself with sea water though ideally it should be with $5 \%$ acetic acid. Routine laboratory investigations show no abnormality except non-significant ST elevation in ECG. The patient was managed conservatively with antihistamine, corticosteroids and antibiotics and recovered completely within four days.
\end{abstract}

[BSMMU J 2014; 7 (2) : 138-140]

\section{Introduction :}

Jelly fish or jellies are the major non-polyp form of the phylum Cnidaria (Coelenterata) containing over 10,000 species of animals, found exclusively in aquatic and mostly marine environment. They consist of a gelatinous umbrella-shaped bell and trailing tentacles (figure 1). The bell can pulsate for locomotion, while stinging tentacles can be used to capture prey. Jellyfish are categorized into four classes, namely, hydrozoa (Portuguese man-of-war), scyphozoa (true jellyfish), cubozoa (box jellyfish, most toxic) and anthozoa (sea anemones and corals) ${ }^{1}$. In 2010 , at a New Hampshire beach, jelly fish stung between 125 and 150 people. In 2006, the Spanish Red Cross treated 19,000 stung swimmers along the Costa Brava. Jelly fish stinging in Bangladesh is rare. Yet, this contact illness might gain importance due to increasing deep sea fishing and ever-growing popularity of seaside tourism. Jelly fish

Address for Correspondence: Mohammad Main Uddin, Department of Medicine, Cox's Bazar Medical College, Cox's Bazar. stinging usually result in three main types of reactions: immediate allergic, immediate toxic and delayed allergic responses ${ }^{2}$. Fatality can occur due to hypersensitivity or can be induced by the effect of various toxins on the cardiovascular system, respiratory centre or kidneys ${ }^{3}$.

\section{Case history :}

Mr. SU, 30 years of age, got admitted to Cox's Bazar Medical College Hospital on 3rd June 2013 with the complaints of severe abdominal pain, bodyache and paresthaesia for 3 hours following contact with 'Nuinna' (local name of jellyfish) tentacles while he was on fishing at sea. Initially he had an intense burning sensation and redness at the site of contact in his left arm. Within few minutes he developed severe central colicky abdominal pain without vomiting or loose motion. He had severe bodyache for the same duration causing difficulty even in moving side to side. He also had paraesthesia along four limbs without paresis or swelling. He has no history of 
fever, cough, breathlessness or other systemic symptoms. On examination, he was anxious, agitated, and drowsy. His pulse is $90 \mathrm{bpm}$, blood pressure $130 / 80 \mathrm{~mm}$ of $\mathrm{Hg}$, respiratory rate 15 breaths/min. He had an erythematous, linear, elevated, tender skin lesion at lateral aspect of his left arm (figure 2), which he mentioned was due to contact with jelly fish tentacle. There was diffuse abdominal tenderness without ascites, organomegaly or mass. Musculoskeletal system revealed severe tenderness in all four limbs without definite arthritis or enthesitis. He was afebrile, not anemic, non-icteric, had no lymphadenopathy or any other skin changes. Examination of other systems revealed no abnormality.

He had normal laboratory findings, including complete blood count, routine liver and renal function tests, creatine phosphokinase, troponin-I, serum amylase and urine routine microscopic examination as well as normal whole abdominal ultrasonography, chest X-ray and plain X-ray abdomen. However his ECG showed ST elevation in chest leads. Though he did not have ischemic chest symptom or raised troponin-I, ECG was repeated after 12 hours, which showed no dynamic change.

The patient was managed with bed rest, IV fluid (stopping enteral feeding), intra-venous (IV) dexamethasone, IV omeprazole, per rectal paracetamol and topical antihistamine. On day 2 , he developed fever and cough, but his abdominal pain subsided. He resumed oral feeding and his new symptoms were treated with paracetamol and oral loratadine. Eventually he improved and was discharged on day 4.

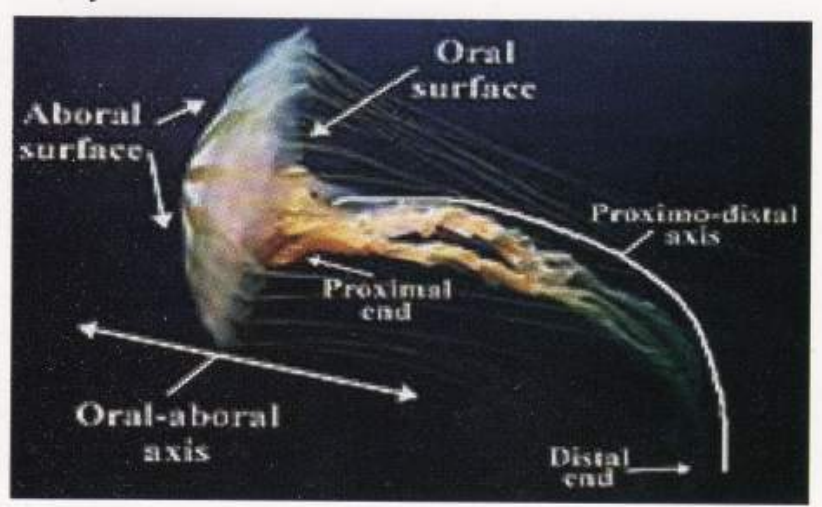

Fig-1: Contact site of jelly fish stinging.

\section{Discussion :}

Stinging jelly fish are found in most open waters and may vary in size from a few millimetres to many meters. Periodically they are found in large numbers and contact with people occurs frequently. Estimated human cases are more than 1 million per year with more than 10 deaths worldwide ${ }^{4}$. In Bangladesh sporadic cases were found in coastal areas including Teknaf and Cox's Bazar. Reactions may vary from mild skin rash to life-threatening symptoms. Lethal species are Indo-Australian box jelly fish, Irukandji, Portuguese man-of-war (Physalia) and Chinese Stomolophus nomurai. Jelly fish have tentacles studded with stinging nematocysts. In the stinging process, nematocysts are released and discharged upon mechan-osensory stimulation. Sting contains toxic peptide, phospholipase A and histamine-liberating factor ${ }^{5}$. Victims usually report immediate prickling or burning, pruritus, paraesthesia and painful throbbing with radiation. The skin becomes reddened, darkened, edematous, and/or blistered. Neurologic, cardiovascular, respiratory, rheumatologic, gastrointestinal, renal and ocular symptoms have been described. Anaphylaxis is possible. Irukandji syndrome, associated with the Australian jelly fish Carukia barnesi and other species is potentially fatal that most commonly is characterized by severe back, chest, and abdominal pain, nausea and vomiting, headache, sweating and, in the most serious cases, myocardial troponin leak and pulmonary edema. This syndrome is thought to be mediated, at least in part, by the release of endogenous catecholamines ${ }^{6}$.

The skin should be decontaminated immediately with a generous application of vinegar (5\% acetic acid). Rubbing alcohol (40-70\% isopropyl alcohol), baking soda (sodium bicarbonate), fresh lemon or lime juice, olive oil or sugar may be effective. For the sting of the venomous box-jelly fish, vinegar should be used. Local application of heat (up to $45^{\circ} \mathrm{C} / 113^{\circ} \mathrm{F}$ ), commonly by immersion in hot water, may be as effective. Perfume, aftershave lotion, and 
high-proof ethanol are not efficacious and may be detrimental. Formalin, ether, gasoline and other organic solvents should not be used. Shaving the skin helps remove remaining nematocysts. Fresh water irrigation and rubbing leads to further stinging by adherent nematocysts and should be avoided. After decontamination, topical application of an anesthetic ointment (lidocaine, benzocaine), an antihistamine (diphenhydramine) or a glucocorticoid (hydrocortisone) may be helpful. Persistent severe pain after decontamination may be treated with morphine, meperidine, fentanyl, or another narcotic analgesic. Muscle spasms may respond to diazepam (2-5 $\mathrm{mg}$, titrated upward as necessary) or $10 \%$ calcium gluconate $(5-10 \mathrm{ml})$ given IV. An ovine-derived antivenom is available from Commonwealth Serum Laboratories for stings from the box-jellyfish found in Australian and Indo-Pacific waters. Our case was typical in presentation except non-significant ST elevation. In this particular case, he was stung in Bay of Bengal. He was paniced, had local and systemic symptoms, but he decontaminated his skin with sea water which is effective ${ }^{7}$. We treated the patient with bed rest, IV fluid, IV dexamethasone, IV omeprazole, per rectal paracetamol, IV ceftriaxone and topical antihistamine. We followed the patient till full recovery and discharged him on day 4 .

\section{Conclusion :}

As Cox's Bazar is a tourist zone, visitors should know about the risk of jelly fish stinging and its first aid treatment. A large number of fishermen are engaged in deep sea fishing and are at risk of contact illness with jelly fish and they must carry vinegar, antihistamine and corticosteroid in the boat. Health care providers in coastal areas of Bangladesh should know about this new health problem including its management.

\section{References :}

1. Cheng D, Dattaro JA, Yakobi R. Jellyfish stings. emedicine 2008.

2. Sintuu C, Richard AJ. Coelenterate and jellyfish envenomations. emedicine 2008

3. Burnett JW, Calton GJ, Burnett HW. Jellyfish envenomation syndromes. J Am Acad Dermatol 1986; 14(1):100-106.

4. S H L Thomas, J White. Poisoning by venomous animal. In: Colledge, Walker, Raltson editors. Davidson's Principles and Practice of Medicine. London; Elsevier Limited, 2010: 223-228.

5. Michael Rawlins, Marine animal poisoning. In: Parveen Kumar, Michael Clark editors. Kumar and Clark's Clinical Medicine. London; Elsevier Limited, 2009: 949-950.

6. Disorders Caused by Venomous Snakebites and Marine Animal Exposures. In: Longo, Fauci, Kasper, Hauser, Jamesen, Loscalzo editors. Harrison's Principles of Internal Medicine. New York; Mc Graw Hill, 2012: Chapter 396.

7. Fenner P, Williamson J, Burnett J, Rifkin J. First aid treatment of jellyfish stings in Australia. Response to a newly differentiated species. Med J Aust 1993; 158 (7): 498-501. 